\title{
Maximization of Solar Hot Water Production Using a Secondary Storage Tank
}

\author{
Mahendra Gooroochurn and Ashwan Visram
}

\begin{abstract}
The use of passive thermosiphon solar water heating ( $\mathrm{SWH})$ is a cost-effective renewable source of energy for hot water production in Mauritius, given the relatively high solar yield year round. However, unavailability of sufficiently hot water for early morning use has been reported in households, confirmed by a survey undertaken, which may be due to improperly sized tank and/or collectors. Backup gas or electric heating is normally installed to cater for this problem. This paper presents the research work performed to analyze the dynamics of hot water production, consisting mainly of monitoring the temperature of the water inside the tank of an actual SWH in operation with the objective of characterizing the factors affecting hot water production. The temperature of the hot water inside the storage tank was found to fluctuate during the day and with consumption of hot water, and the mixing of mains cold water with the hot water was deemed to be a major factor leading to the shortage of hot water the next morning. Based on the analysis, a passive thermosiphon SWH in use in a household was modified by adding a second hot water tank with associated solenoid-actuated valves modulated by a microcontroller to regulate flow between the two tanks and to the end use point according to an appropriate rule set. The results show that hot water production can be optimized in currently installed SWH systems with the proposed design without back-up heating systems, thus providing an effective retrofit solution to systems in use.
\end{abstract}

Index Terms-Solar thermal, hot water storage, solar hot water maximization.

\section{INTRODUCTION}

The tropical climate prevailing in Mauritius is marked by a cool dry winter ranging between June to September and a warm humid summer from November to April. The amount of solar radiation experienced by the island is generally reported as $6 \mathrm{kWh} / \mathrm{m}^{2} /$ day, with about 6 to 8 hours of bright sunshine daily, which is classified in the medium-high range, making Mauritius a good candidate for making use of solar thermal and solar PV systems to generate clean energy.

With the increase in the prices of electricity and gas, consumers in Mauritius have progressively shifted towards solar water heating systems, with government offering grants to encourage this transition, although less than $20 \%$ of households are equipped with SWH as per data provided by Statistics Mauritius [1]. As per the National Audit Office's audit report [2], the Government of Mauritius is providing grant schemes to householders to encourage the use of renewable energy through SWH.

Manuscript received November 14, 2018; January 24, 2019.

M. Gooroochurn and A. Visram are with the Faculty of Engineering, University of Mauritius, 80837 Reduit, Mauritius (e-mail: m.gooroochurn@uom.ac.mu and ashwan.visram@umail.uom.ac.mu respectively).
However, the use of SWH came along with shortcomings. As per the critical review made by Chaudhari, et al. [3], one of the drawbacks is that the water heats up only when sunlight is available. Moreover, on highlands, the collectors are not able to absorb enough solar radiation to heat the water since it is often cloudy. The stochastic nature of solar radiation makes accurate SWH design as per a given user's hot water demand difficult with the consequence that the ability of the SWH system to produce enough hot water above a minimum temperature cannot be assured when used without any backup.

From the reviews made by Shukla, et al. [4], another weakness relates to the design and specification of a passive thermosiphon SWH storage tank. Indeed, this type is more common in Mauritius. In this system, upon usage of the warm water in the storage tank, the latter is instantaneously topped up with cold water up to a maximum level. This method of administering cold water inside the hot water tank dilutes the temperature of the hot water inside the storage tank which is to the detriment of hot water buffering for periods of low sunshine or no sunshine, e.g. during cloudy periods or at night.

Another concern with inability to achieve a minimum temperature is Legionella. Legionella is a bacteria that causes pulmonary diseases and grows in water, thus posing a serious health issue as water produced from SWH is used for potable ends, including washing of utensils and drinking. Legionella stops growing at $55^{\circ} \mathrm{C}$, therefore to minimize the risk of presence of Legionella, the temperature of water stored in the SWH should be kept above $60^{\circ} \mathrm{C}$.

The aim of this paper is to analyze a passive thermosiphon SWH, currently being in use in a household, wherein the factors affecting the hot water production will be investigated and evaluated. The overall aim is to propose a design retrofit to existing SWH to maximize the amount of hot water output from the SWH, thereby reducing or eliminating the need for backup nonrenewable heating sources such as gas or electric heating.

\section{LITERATURE REVIEW}

Improvement in the performance of solar water heaters has been the subject of research efforts from different perspectives of solar water system design. Robles et al. [5] studied the use of aluminium mini-channel tubes compared to conventional copper flat plate collectors, and obtained a $13 \%$ improvement in performance. Similarly, Benrejeb et al. [6] investigated an integrated collector storage system with improved optical and thermal properties so that more hot water can be produced per unit collector area to reduce the size of the system and hence the system manufacturing cost 
Huang et al. [7] used phase change material as part of the solar water heating system design and reported enhanced heat storage capacity, which can be an interesting solution to address the low early morning temperature observed, as confirmed by the work of Felinski et al. [8]. Shirinbakhsh et al. [9] also researched into the benefit of phase change material with respect to a non-uniform daily water consumption and concluded that integration of PCM can increase the annual solar fraction (ASF) by $4 \%$. As concluded by Mumtaz et al. [10] in their review of solar collector designs for thermal energy storage, increasing the surface contact area between the PCM and the absorber plate is determinant in increasing outlet temperatures.

Ka-Kui Tse et al. [11] proposed a parallel circular tube ring type heat exchanger for an indirect thermosiphon solar water heating system, and showed through experimental and simulation results that the thermal efficiency can be increased in this way. Gao et al. [12] performed parametric analysis of the factors affecting the thermal performance of U-pipe evacuated solar tube collector and produced a set of recommendations for improving the efficiency of the collectors, including the influence of length of tube, mass flow rate and heat loss coefficient on thermal efficiency. Bracamonte et al. [13] studied the influence of collector tilt angle on solar heat gain, flow inside the tank and stratification, concluding that low tilt angles lead to high solar gain and significant stratification, whereas at $45^{\circ}$, the content of the storage is fully mixed.

Ataee et al. [14] adopted an energy and exergy approach to model the factors affecting the performance of evacuated solar collector tube, concluding that selective coating absorber tube is an effective method to improve the outlet temperature of the tube. Liu et al. [15] investigated the thermal performance of various combinations of extrinsic properties of evacuated tube solar water heater system using machine learning techniques, and showed that two of their selected configurations produced higher heat collection rates than previous recorded data. Bouhal et al. [16] used computational fluid dynamics to assess the efficacy of using a flat plate at various positions and inclination inside the solar water tank to improve stratification. They concluded that a flat plate at middle height level yielded a better thermal performance.

Eze and Ojike [17] carried out an analysis of the thermal efficiency of a passive solar water heater consisting of a single-glazed Flat Panel Collector (FPC). The experiment was carried out at Nsukka in Nigeria under daytime conditions. The ambient temperature during the course of this investigation ranged from $21^{\circ} \mathrm{C}$ to $31^{\circ} \mathrm{C}$, and the daily irradiation ranged from $8.3 \mathrm{MJm}-2$ to $17.4 \mathrm{MJm}-2$. From the investigation, it was found that the peak temperature of the heated water at the outlet of the system was about $83^{\circ} \mathrm{C}$. The graph in Fig. 1 show the results obtained during the investigation. The graph depicts the hourly solar radiation and ambient temperatures for the study period, from March 17, 2010 up to March 21, 2010. Ta represents the ambient temperature and $\mathrm{G}$ is the solar radiation. The subscripts 1,2, $3,4,5$ correspond to the 17 th, 18th, 19th, 20th and $21 \mathrm{st}$ March, respectively. It was noted that the ambient temperature rises as the solar radiation reaches its peak.

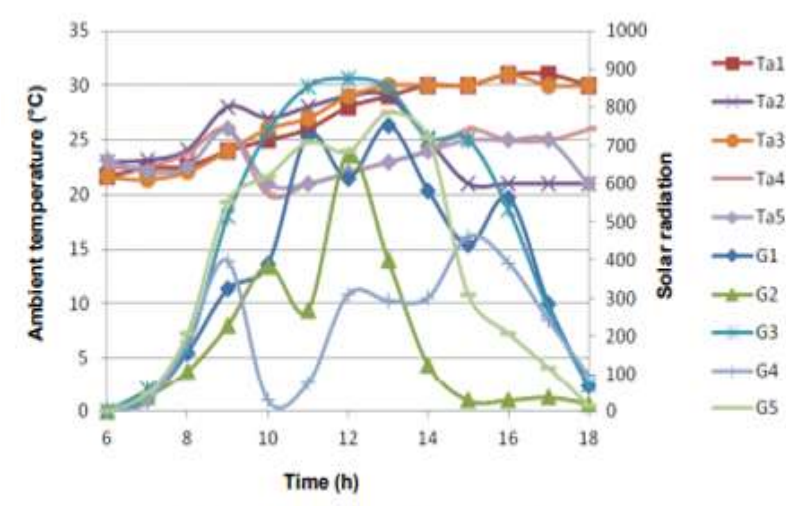

Graph of solar radiation and ambient temperature against time.

Fig. 1. Results from test on passive thermosiphon, Eze and Ojike [17].

The graph in Fig. 2 shows the variation of hot water temperature produced (Tfo) from the collector with time. Comparing both graphs, it can be observed that the hot water temperature fluctuates steadily in synchrony with the solar radiation.

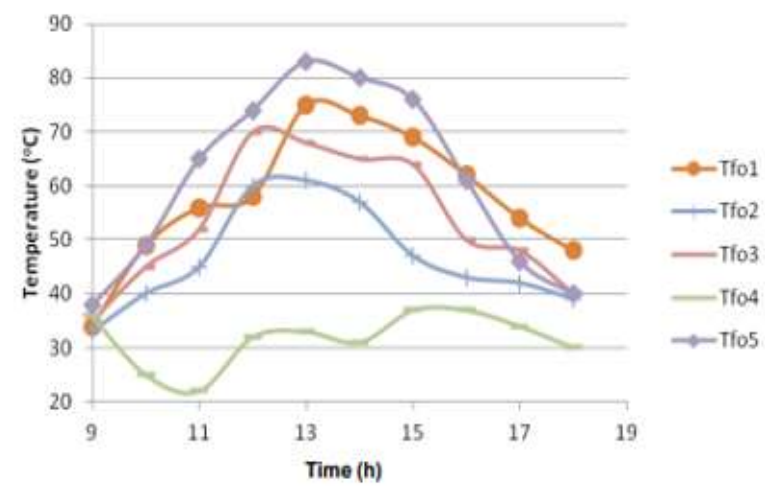

Fig. 2. Variation of hot water temperature (Eze and Ojike, 2012).

In an attempt to analyze an active and a passive solar heating system in Pakistan, Samo et al. [18] made use of a fabricated FPC to investigate the temperature outlet from an active and a passive SWH for 2.5 hours. In this experiment, it was assumed that the solar radiation received by the earth is $795 \mathrm{~W} / \mathrm{m}^{2} /$ hour and that Pakistan is exposed to 7 hours of bright sunshine per day. The outlet temperature for an active $\mathrm{SWH}$ in moderate weather was $76^{\circ} \mathrm{C}$ with an inlet temperature of $25^{\circ} \mathrm{C}$. For the passive $\mathrm{SWH}$, the maximum temperature achieved by this system in moderate weather was $90.5^{\circ} \mathrm{C}$ with an inlet temperature of $28.1^{\circ} \mathrm{C}$.

The graph below demonstrates the results obtained by Samo et al. [18] for the experiment carried out on an active $\mathrm{SWH}$, where it can be seen that the temperature of hot water at the outlet increases with increasing time of the day.

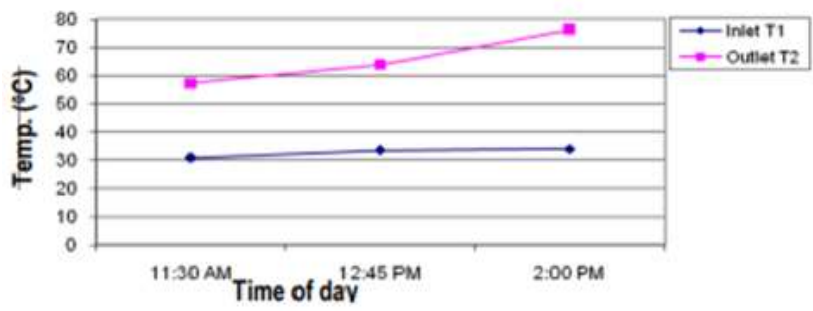

Fig. 3. Relationship between inlet and outlet temperatures, Samo et al. [18]. 


\section{DATA COLlECtion AND ANALYSIS}

An in-use SWH, located in the North-East of Mauritius was used for collecting hot water temperature profiles. The temperature and consumption of hot water inside the storage tank was monitored. These data will enable to ascertain the effect of the time of the day and the consumption of hot water on the temperature of hot water for a typical SWH in use. Some important information on the SWH under study are as follows:

\section{Site location: Riviere du Rempart \\ Orientation: Facing North \\ Feed type: Gravity \\ Flow type: Passive thermosiphon \\ SWH collector type: Evacuated tubes \\ Number of tubes: 20 \\ Storage tank: 240L, non-pressure type \\ Tank outer diameter: $470 \mathrm{~mm}$ \\ Length of tank: $1800 \mathrm{~mm}$}

PT100 (Platinum Temperature Resistance) temperature sensors were used to monitor the temperature of hot water inside the storage tank. Due to the thermosiphon process taking place inside the SWH and stratification, the temperature of water is expected to vary with depth inside the solar water tank. Therefore, three PT100 temperature sensors were used. The temperature sensors were attached to an Aluminium rod at specific heights as shown in Fig. 4. An average of the three measured temperatures was calculated and logged on an Arduino Uno microcontroller board. A Hall Effect sensor (YF-S201) was used to monitor the flow rate of water flowing to the tank and the amount of hot water consumed. The flow rate measurement from the flow meter was logged via the Arduino Uno microcontroller board.

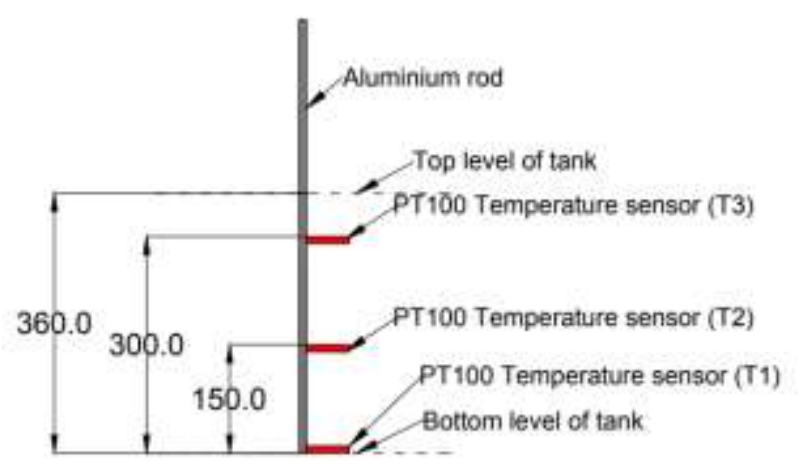

Fig. 4. Placement of temperature sensors.

It should be noted that the flow sensor is fixed at the inlet of the storage tank. The value of cumulative total will be the same at the outlet and the inlet since as the level of water in the storage tank decreases, the storage tank is filled until a high level is achieved again. The variation of the temperature of water at the bottom (T1), middle (T2) and upper (T3) portions of the tank are shown in Figure 5. In addition, the average temperature for the three temperatures at each time interval is also included on the graph.

The maximum temperature is at the middle of the tank since cold water is supplied to the tank from the top thereby, decreasing the temperature of the water at the top of the tank. Moreover, the temperature of water inside the tank increases during the day and rather stabilizes at night. Another point to be noted is that the temperature of the water in the tank fluctuates continuously and that the recommended temperature of $60^{\circ} \mathrm{C}$ is very rarely achieved. This can be accounted by the current location of the SWH.

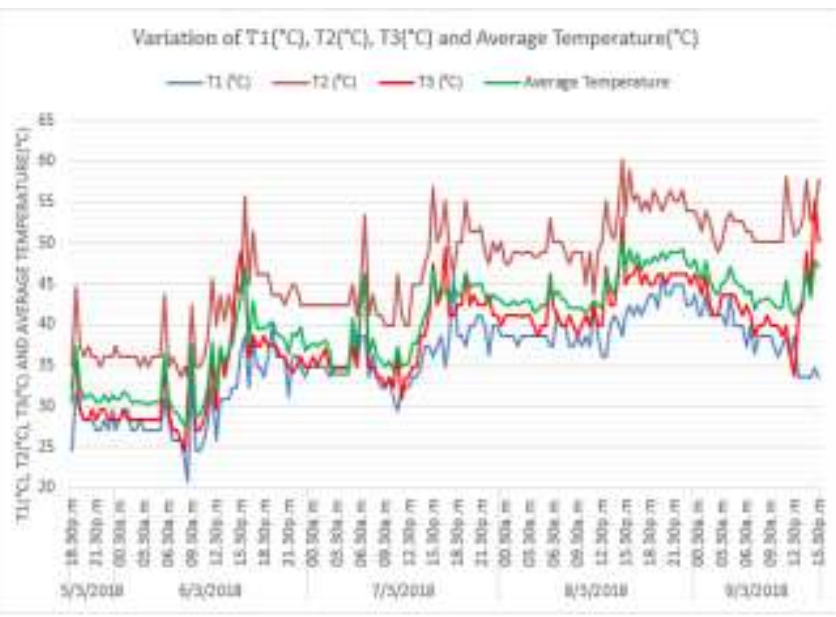

Fig. 5. Experimental results on variation of temperature.

The SWH system is not exposed to direct sunshine throughout the day since it is situated at a fairly low level and is surrounded by houses and trees, which shows that site factors remains an important factor to be considered in accounting for poor performance or unavailability of hot water as per customer requirements, and the need to train SWH installers in carrying out a proper site assessment. Despite these sub-optimal design elements, the experiment was pursued to investigate potential improvement in hot water production through design retrofits, and the results will be applicable to periods of low sunshine or bad weather.

Fig. 6 shows the variation of the cumulated profile for the amount of hot water consumed during the investigation period. Around 1150 liters of hot water were consumed during the three days amounting to 380 liters of daily consumption.

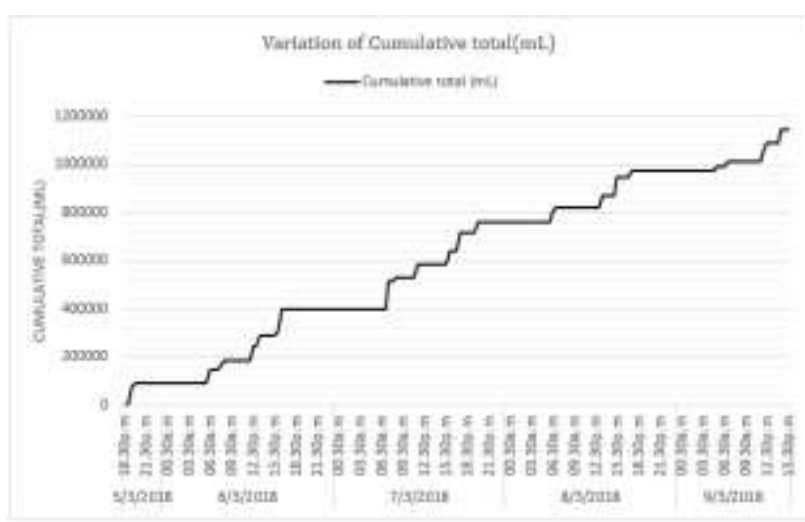

Fig. 6. Cumulated hot water consumption

The temperature variations obtained are illustrated in Fig. 7. As expected it can be seen that the temperature of the water inside the storage tank falls when hot water is taken from the system, mainly due to instant mixing with cold water. Thus, the cold water mixes with the hot water present initially thereby, decreasing the temperature of the water inside the tank. From the graphs, it can be seen that at times, the temperature decreases by almost $10^{\circ} \mathrm{C}$. 


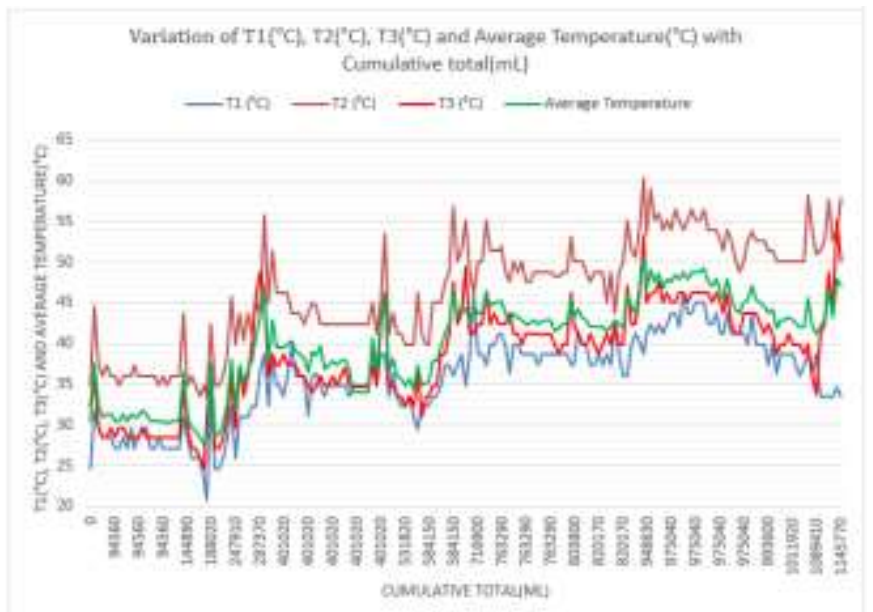

Fig. 7. Temperature variation with volume of hot water consumed.

\section{IMPROVEMENT OF ACTUAL SWH}

The proposed retrofit to the existing SWH is shown in Fig. 8.

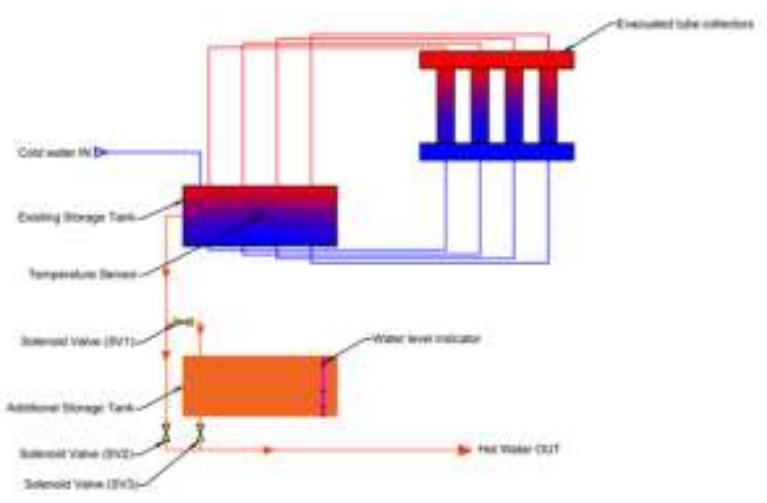

Fig. 8. Process Flow Diagram of retrofitted SWH.

The experimental set-up consists of an additional solar water tank, three solenoid valves, a water level indicator in the additional tank and a PT100 temperature sensor located in the middle of the existing storage tank. The position of the probes inside the additional tank is as shown below.

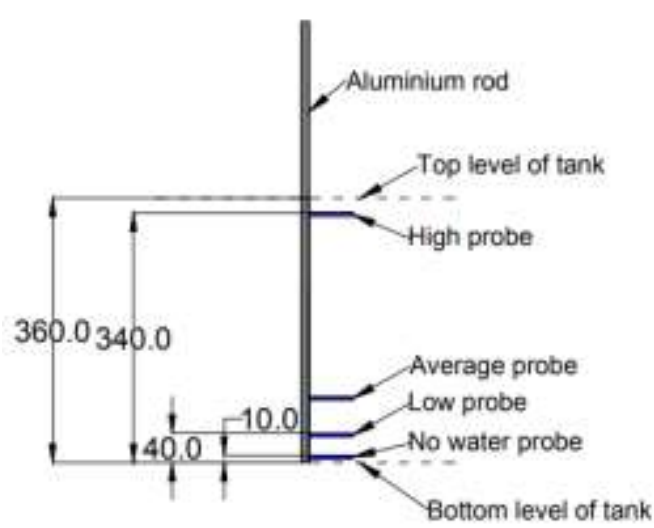

Fig. 9. Probe location in the additional tank.

The rule set used to control the states of the solenoid valves with respect to the different conditions that prevail in the system are given in Table I. The states of the solenoid valves have been set to ensure that water above the preset temperature is supplied as much as possible to the user. The components to be used as retrofits to the existing SWH for maximizing hot water production were then assembled and connected to the existing SWH as shown in the layout of Fig. 10. The total cost of implementation for the project was MUR 12332 (approx. \$350).

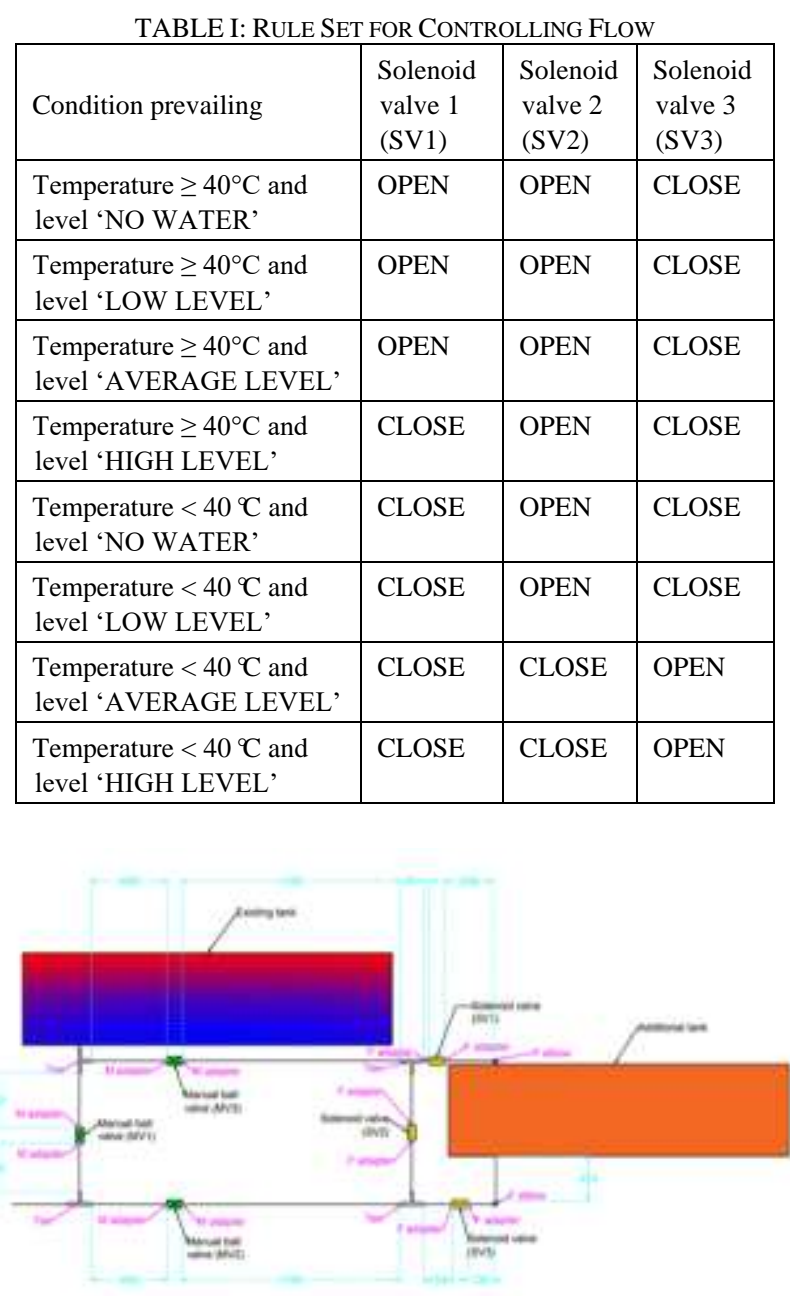

Fig. 10. Physical layout of system components.

\section{Testing And Evaluation}

The main test carried out was the temperature monitoring of hot water inside the additional tank after the implementation of the proposed solution. The test began after the setting up of the proposed system and lasted for three days. It involved the use of two PT100 temperature sensors placed inside the additional tank. The variation of the temperature of water at the low position (T2) and the high position (T1) is shown in Fig. 11 as well as the average temperature.

The temperatures at low and high levels of the tank are close to each other throughout. At the start, both temperatures increase since the additional tank is being replenished up to the high level indicator. Both temperatures then fall and stay low for almost 12 hours. This may be attributed to the use of the hot water from the additional tank during the night after the setting up of the system, which resulted in a low level of hot water inside the additional tank. After that, the temperature increases again, showing that the tank has been replenished. 


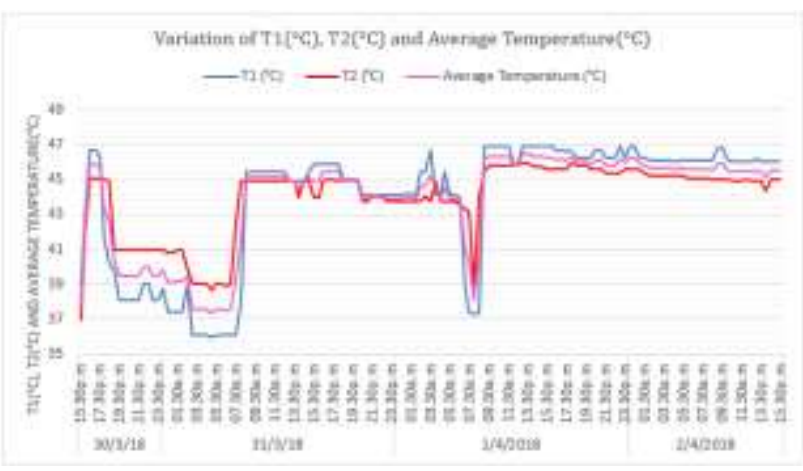

Fig. 11. Temperature variation in retrofitted SWH.

A rather constant temperature is observed in the tank afterwards up to the 1st of April at around 6.00 a.m, after which water has been used from the additional tank. The graphs also depict that the temperature of the water does not fluctuate during the night.

To have a better understanding of the fluctuations in temperature inside the additional tank, the water consumption curve previously obtained in the investigation section is fitted to the temperature values obtained in the test. The period to be considered in the test results is therefore, 31st March 2018 at 9.00 a.m. up to 2nd April 2018 at 15.30 p.m. Likewise, the data values selected from the investigation is for the period, 6th March 2018 at 9.00a.m up to 8th March 2018 at 15.30 p.m.

The variation of the temperature of water at the low level (T2) and the high level (T1) inside the additional tank as water is being consumed is shown in Fig. 12.

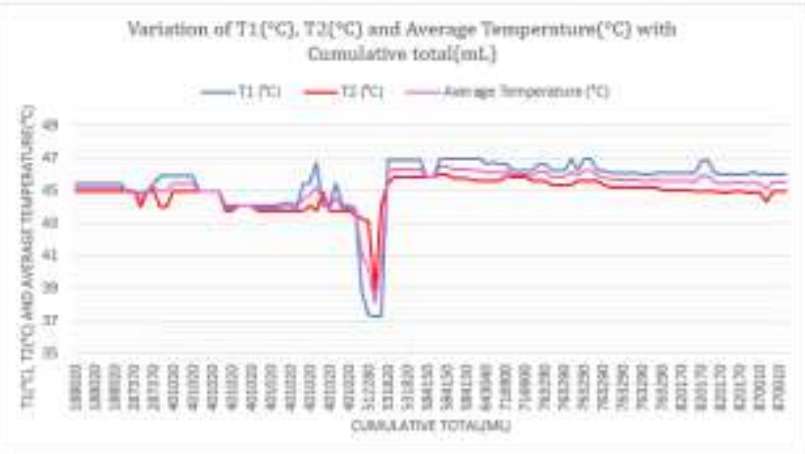

Fig. 12. Variation of temperature with cumulative water use.

The valley in the graphs indicates that there is a decrease in the temperature of the water inside the tank when water is being consumed. The decrease in temperature may be due to a low level of water inside the additional tank. Having a low level of water inside the tank disables the contact of the sensors with the water since both of the sensors are situated above the low-level indicator probe.

For further investigations and better comparison between the initial system and the modified one, the temperatures obtained from the first test and the temperature of water in the middle of the initial tank obtained previously in the investigation section are plotted on the same graph.

The variation of the temperature of water at the low position (T2-ADDITIONAL) and the high position (T1-ADDITIONAL) of the additional tank is shown in Figure 13. The average (AVERAGE TEMPERATURE ADDITIONAL) of the two temperatures at each time interval is also illustrated. The middle temperature (T2-INITIAL SYS) inside the storage tank of the initial system is added to the graph.

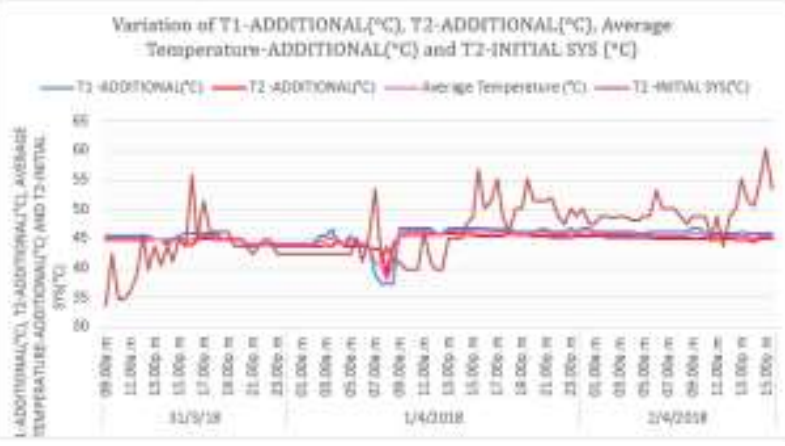

Fig. 13. Comparing retrofitted and existing systems.

As per the graphs, the temperature of the water inside the additional tank follows a constant pattern such that the temperature of the water inside the additional tank is always available above $40^{\circ} \mathrm{C}$ throughout the day. However, it has been observed that the temperature in the middle of the tank for the initial system seems to change continuously. For the initial system, it was noted that the temperature increases during the day and decreases during peak hours thereby, not always supplying water at the desired temperature.

The cumulative total water consumption curve previously obtained in the investigation section is fitted to the temperature values obtained in the test. The curve for the temperature of water in the middle of the initial tank as obtained previously in the investigation section is also included on the same graph (Fig. 14).

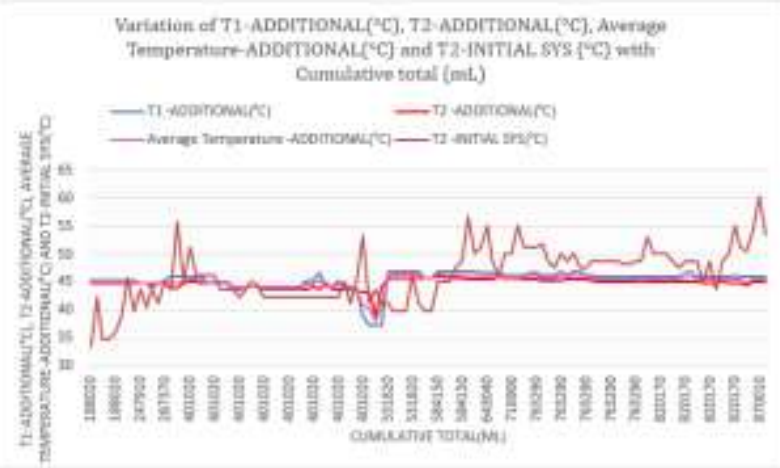

Fig. 14. Temperature variation with respect to hot water use.

The variation of the temperature of water at the low position (T2-ADDITIONAL) and the high position (T1-ADDITIONAL) inside the additional tank as water is being consumed is illustrated as well as the average temperature (AVERAGE TEMPERATURE-ADDITIONAL) of the two temperatures. The middle temperature (T2-INITIAL) inside the storage tank of the initial system as water is being consumed has also been added.

From the above graph, it has been observed that the temperature of water inside the additional tank decreases after being supplied. Furthermore, the temperature at the middle of the existing tank in the initial system decreases more as compared to temperature inside the additional tank when the latter is supplying hot water.

Additionally, the temperature in the middle of the existing 
tank fluctuates throughout the day. This affects the user because water having a temperature below $40^{\circ} \mathrm{C}$ is deemed unsuitable for shower purpose.

\section{CONCLUSIONS}

The results obtained proved that the temperature of water inside the SWH is affected by the time of the day and by the rate of hot water consumption. Using proper redesign and controls, it was found that it is possible to obtain and maintain a constant temperature of water throughout a day from a SWH, thereby maximizing the hot water output.

When carrying out the investigation on an actual SWH, it was found that the temperature of water extracted for use did not reach the expected and recommended temperature of $60^{\circ} \mathrm{C}$, due to wrong siting and orientation of the SWH. Therefore, proper siting of the solar water collectors is a pre-requirement to achieving maximized hot water from the SWH. The results obtained showed that hot water production can be optimized using the proposed retrofits. Moreover, the dynamics of the SWH can be modelled to produce an accurate model of the SWH based on experimental data. This model can then be used as a means of predicting temperature inside an SWH tank in any location and evaluate the adequacy of the proposed retrofits as a substitute for backup heating. The effect of the temperature and water level set points used for controlling the operation of the solenoid valves will be investigated further using machine learning techniques to come up with combinations which further maximize the production of hot water.

\section{ACKNOWLEDGMENT}

The authors would like to thank the technical staff of the Mechanical and Production Engineering Department at the University of Mauritius for their contribution in setting up the experimental installation and for providing solar radiation data.

\section{REFERENCES}

[1] Statistics Mauritius, Digest of Energy and Water Statistics, 2016.

[2] National Audit Report, "Moving towards Renewable Energy-SOLAR Water Heater Grant Scheme," Ministry of Social Security, National Solidarity, and Environment and Sustainable Development, February 2017.

[3] S. Chaudhari, N. Parmar, N. Hitesh, and H. N. Panchal, "A Critical Review on Solar Water Heater," International Journal of Advanced Engineering Technology, vol. 4, no. 2, pp. 50-52, April-June 2013.

[4] R. Shukla, K. Sumathy, P. Erickson, and J. Gong, "Recent advances in the solar water heating systems: A review," Renewable and Sustainable Energy Reviews, October 30, 2012.

[5] A. Robles, V. Duong, A. J. Martin, J. L. Guadarrama, and G. Diaz, "Aluminum minichannel solar water heater performance under year-round weather conditions," Solar Energy, vol. 110, pp. 356-364, 2014.

[6] R. Benrejeb, O. Helal, and B. Chaouachi, "Optical and thermal performances improvement of an ICS solar water heater system," Solar Energy, vol. 112, pp. 108-119, 2015.

[7] K. Huang, G. Feng, and J. Zhang, "Experimental and numerical study on phase change material floor in solar water heating system with a new design," Solar Energy, vol. 105, pp. 126-138, 2014
[8] P. Felinsk and R. Sekret, "Effect of PCM application inside an evacuated tube collector on the thermal performance of a domestic hot water system," Energy and Buildings, vol. 152, pp. 5581567, 2017.

[9] M. Shirinbakhsh, N. Mirkhani, and B. Sajadi, "A comprehensive study on the effect of hot water demand and PCM integration on the performance of SDHW system," Solar Energy, vol. 159, pp. 405-414, 2018.

[10] M. Mumtaz A. Khan, Nasiru I. Ibrahim, I. M. Mahbubul, H. M. Ali, R. Saidur, and F. A. Al-Sulaiman, "Evaluation of solar collector designs with integrated latent heat thermal energy storage: A review," Solar Energy, vol. 166, pp. 334-350, 2018.

[11] K. K. Tse and T. T. Chow, "Dynamic model and experimental validation of an indirect thermosyphon solar water heater coupled with a parallel circular tube rings type heat exchange coil," Solar Energy, vol. 114, pp. 114-133, 2015

[12] Y. Gao, R. Fan, X. Y. Zhang, Y. J. An, M. X. Wang, Y. K. Gao, and Y $\mathrm{Yu}$, "Thermal performance and parameter analysis of a U-pipe evacuated solar tube collector," Solar Energy, vol. 107, pp. 714-727, 2014.

[13] J. Bracamonte, J. Parada, J. Dimas, and M. Baritto, "Effect of the collector tilt angle on thermal efficiency and stratification of passive water in glass evacuated tube solar water heater," Applied Energy, vol. 155 , pp. 648-659, 2015.

[14] S. Ataee and M. Ameri, Energy and exergy analysis of all-glass evacuated solar collector tubes with coaxial fluid conduit, Solar Energy 118 (2015) 575-591, 2015.

[15] Z. J. Liu, H. Li, K. J. Liu, H. C. Yu, and K. W. Cheng, "Design of high-performance water-in-glass evacuated tube solar water heaters by a high-throughput screening based on machine learning: A combined modeling and experimental study," Solar Energy, vol. 142, pp. 61-67, 2017.

[16] T. Bouhal, S. Fertahi, Y. Agrouaz, T. El Rhafiki, T. Kousksou, and A Jamil, "Numerical modeling and optimization of thermal stratification in solar hot water storage tanks for domestic applications: CFD study," Solar Energy, vol. 157, pp. 441-455, 2017.

[17] J. I. Eze and O. Ojike, "Analysis of thermal efficiency of a passive solar water," International Journal of Physical Sciences, vol. 7, no. 22, pp. 2891-2896, June 9, 2012.

[18] S. R. Samo, A. A. Siyal, Z. A. Siyal, and A. R. Jatoi, "Analysis of an Active and Passive Solar Water Heating," in Proc. Sixteenth International Water Technology Conference, IWTC, 2012.

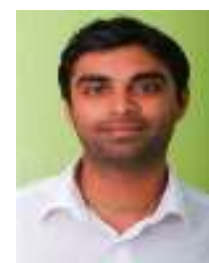

M. Gooroochurn holds a BEng(Hons), an MSc and a $\mathrm{PhD}$ in Mechatronics. He is a LEED accredited professional in green building design and construction (LEED AP BD+C). He currently works as lecturer in the Mechanical and Production Engineering Department, Faculty of Engineering at the University of Mauritius, and his research interests are in sustainability in the built environment and renewable energy systems design and integration.

$\mathrm{He}$ has published journal papers related to pattern recognition and machine learning, machine vision and sustainable development in the built environment as well as guidebooks for the industry in green roof and stormwater management. He has also published books including:

1. Introduction to Digital Logic \& Boolean Algebra: A Comprehensive Guide to Binary Operations, Logic Gates and Number Representations in Digital Technology, Amazon Kindle eBook, ASIN B01HTMBRC6

2. Creating and Training Neural Networks with Excel®: A step-by-step guide to selecting and developing neural networks for your applications, Amazon Kindle eBook, ASIN B01IN865GI

3. Design of a Data Analyser for Ethernet Packets Using VHDL: Analysis and Representation of Ethernet Communication Protocol Using Finite State Machines with VHDL Programming, LAP LAMBERT Academic Publishing, ISBN 978-3659826948

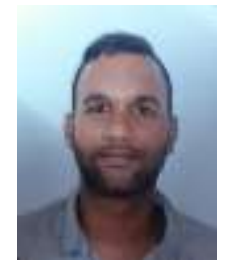

A. Visram holds a BEng(Hons) in mechanical engineering (minor: energy systems). He is actually employed as supervisor SGS Vehicle Examination Centre, Mauritius, where he has the opportunity to apply and develop his passion for automotive engineering. 